\title{
Association between symptom experiences with bio- physiological parameters of haemodialysis patients during AV-fistula cannulation
}

\author{
Rachel K ${ }^{1}$, Nalini SJ ${ }^{2}$ and Revathi $\mathrm{R}^{3 *}$ \\ ${ }^{1}$ Nursing student, Faculty of Nursing, Sri Ramachandra Institute of Higher Education and Research. Porur, Chennai-600116, India \\ ${ }^{2}$ Principal and Professor, Faculty of Nursing, Sri Ramachandra Institute of Higher Education and Research, Porur, Chennai-600116, India \\ ${ }^{3}$ Assistant Professor, Faculty of Nursing, Sri Ramachandra Institute of Higher Education and Research. Porur, Chennai-600116, India
}

\begin{abstract}
Background: Haemodialysis patients usually have symptoms of either mentally or physically experienced before or during or after their procedure. This study evaluates the frequency of experienced symptoms, negatively effect of functioning, regardless of acuity, and well-being can be measured in terms of bio physiological parameters as BP, Pulse rate, Respiratory rate and $\mathrm{SpO} 2$.
\end{abstract}

Methods: In this study convenience sampling technique was used to correlate the symptom experiences and bio-physiological parameters of 200 hemodialysis patients using one to one interview with the set of framed symptoms.

Results: During AV Fistula cannulation, the major symptoms seen were fear, anxiety, irritation, anger and sadness. The main physical symptom experiences by HD patients was pain, drowsiness, fatigue, headache, palpitations, numbness, nausea/vomiting and, breathlessness. There was increase in pulse rate, blood pressure, heart rate, and decrease in the respiratory rate in majority of patients. The most relevant and highly significant were pulse rate due to fear and irritation and increase in hear rate and respiration due to pain and breathlessness.

Conclusion: This study suggests that nursing and physicians' team should consider reducing problems of haemodialysis patients by training and counselling. More is warranted to improve the quality of life which can be resulted from exercise counselling and encouragement in hemodialysis patients.

\section{Introduction}

The kidneys are vital organs perform an incredibly wide array of functions which are essential and have obvious logical and necessary connections for life. Chronic renal failure results in serious clinical symptoms due to wide variety of diseases which results in a permanent failure of the excretory, regulatory and hormonal (metabolic) functions of the kidney $[1,2]$. Chronic kidney disease (CKD) is kidney damage or defective glomerular filtration rate (GFR) for 3 months or more irrespective of the cause [3]. The progressive worsening of kidney function is considered as end stage renal disease (ESRD) at that point a person requires dialysis or transplantation of a functional kidney to survive [4]. ESRD is the end stage with glomerular filtration rate coming down to less than $5 \%$ to $10 \%$ of normal [5].

Kidney failure is a chronic situation and leads to systemic complex situation in human body as it not involved itself but also slowly harms the functioning of the other body organs and thereafter the treatment relies on patient self-management including hospital aspects of care [6]. Due to decreased kidney function which affects many other body organs, dialysis patients experience numerous symptoms, including some serious in terms of medical outcomes $[7,8]$. Hemodialysis is the first choice of therapy for many patients as maintenance therapy otherwise patients may need a kidney transplant that needs dialysis intensely. Hemodialysis is basically require and involves fluid removal side effects by removing too much fluid and include fatigue, low blood pressure, leg-cramps, chest pains, headaches and nausea. These symptoms can persist post treatment for long time as the dialysis is also a continuous process. Apart from theses side effect hemodialysis may expose their circulatory system to microbes, which can lead to bacteraemia which may be affecting the heart valves (endocarditis) in severe infection or affecting the bones (osteomyelitis) [9-14].

A few researchers are performed to evaluate the quality of life of those individuals coping with the stresses due to chronic and lifethreatening illness such as kidney failure and haemodialysis [15]. The concept of QOL is now important aspect of health care with realization that being well is too important to consideration when patients are being treated [16]. The first attempt to visualize QOL was done by the WHO (1947) by defining health as a complete social well-being states including healthy physical and mental status and not merely the absence of disease [17]. HD patients usually have symptoms either mentally or physically experienced before or during or after their HD. Most of the patients might also resemble symptomatic changes to be associated

${ }^{*}$ Correspondence to: $\mathrm{R}$ Revathi, MSc $(\mathrm{N}), \mathrm{PhD}$, Assistant Professor, Faculty of Nursing, Sri Ramachandra Institute of Higher Education and Research, Porur, Chennai-600116, India, E-mail: revathisriraghu@yahoo.co.in

Key words: haemodialysis, quality of life, exercise, counselling

Received: January 07, 2019; Accepted: January 30, 2019; Published: February 04,2019 
with the bio-physiological parameters too as correspondingly [18]. So this associational study used self-reports of haemodialysis patients to catalogue symptoms and to correlate the bio-physiological parameters to evaluate frequently experienced symptoms, negatively effect of functioning, regardless of acuity, and well-being is measured in terms of bio physiological parameters as BP, Pulse rate, Respiratory rate and $\mathrm{SpO}$ 2.Study assay the association of the symptom experiences, bio-physiological parameters of haemodialysis patients with selected demographic variables.

\section{Methodology}

This study was conducted at the F2 dialysis ward out-patient department of Sri Ramachandra Medical Centre, Porur, Chennai-116. Ethical permission was obtained from the Institutional Ethical Committee (students) of Sri Ramachandra Medical College and Research Institute. The physical setting of the $\mathrm{f} 2$ dialysis ward is situated in the $2^{\text {nd }}$ floor of Sri Ramachandra Medical Centre and per day $<50$ are admitted in the ward for hemodialysis procedure. It has 80 bed and 4 bays.

\section{Sampling technique}

In this study convenience sampling technique was used to select 200 samples for Sri Ramachandra Medical Centre. The sample was those who attended in F2 dialysis ward out-patient department.

\section{Sample}

Hemodialysis patients who fulfilled the inclusion criteria and admitted for hemodialysis in the F2 dialysis ward of Sri Ramachandra Medical Centre, Porur, Chennai-116

\section{Criteria for selection of samples}

Inclusion criteria: Patients aadmitted for hemodialysis, aged between 21-60 years able to communicate in English and Tamil and willing to participate in the study

Exclusion criteria: Patients who are not willing to participate in the study and on temporary vascular access

\section{Description of the tool}

The tool consists of three sections, such as

Part 1 Demographic variables of women-It consists of age, sex, education, occupation, family income per month, period of AV fistula, number of HD per week, sources of psychological support, use of diversional therapy, duration of illness. Each of the demographic variables is marked according to patient's verbalisation.

Part 2 Symptom experiences of HD patients- Structured, validated schedule interview by the researcher with a set of framed symptoms reviewed from literature. It consists of two parts, the first part comprising of mental symptoms such as fear, anxiety, irritation, anger, sadness, uncertainness. The second part comprising of physical symptoms such as pain, drowsiness, fatigue, headache, palpitations, numbness, nausea/vomiting, breathlessness. Each of the symptoms is marked either with a yes or no verbalization of the patients that they experience during the cannulation.

\section{Part 3 Bio-physiological parameters}

During the time ofAV Fistula cannulation of HD patients, the bio-physiological parameters like Pulse rate, Respiratory rate, Blood pressure, $\mathrm{SpO} 2$ will be assessed before dialysis, during dialysis and after
Table 1. Interpretation of bio-physiological parameters

\begin{tabular}{|c|c|c|c|}
\hline $\begin{array}{c}\text { Bio-physiological } \\
\text { parameters }\end{array}$ & $\begin{array}{c}\text { Normal } \\
\text { level }\end{array}$ & $\begin{array}{c}\text { Increase } \\
\text { level }\end{array}$ & $\begin{array}{c}\text { Decrease } \\
\text { level }\end{array}$ \\
\hline Pulse rate & $70-99 \mathrm{bpm}$ & $<100 \mathrm{bpm}$ & $>69 \mathrm{bpm}$ \\
\hline Blood pressure & $110 / 70-120 / 80 \mathrm{mmhg}$ & $<130 / 90 \mathrm{mmhg}$ & $>100 / 60 \mathrm{mmhg}$ \\
\hline Heart rate & $70-99 \mathrm{bpm}$ & $<100 \mathrm{bpm}$ & $>69 \mathrm{bpm}$ \\
\hline Respiration rate & $18-20 \mathrm{breaths} / \mathrm{mt}$ & $<21 \mathrm{breaths} / \mathrm{mt}$ & $>17 \mathrm{breaths} / \mathrm{mt}$ \\
\hline SpO2 & $90-100 \%$ & - & $>89 \%$ \\
\hline
\end{tabular}

dialysis. Here increased levels of the bio-physiological parameters are assessed. Bio-physiological parameters were evaluated as given in Table 1.

\section{Data collection procedure}

The researcher planned to collect information from the subjects by using one to one interview with the set of framed symptoms reviewed from literature. The questions were formulated, and options were determined under each question. Data collection was done in July 2017. Each day 15 study subjects were administered the set of framed questionnaires to correlate the symptom experiences and biophysiological parameters and their doubts were clarified. During data collection, the investigator introduced herself to the HD patients first then selected the patients according to the inclusion criteria. Proper and detailed explanation was done in either Tamil or English regarding the study and its benefits. HD patients were assured that no harm will occur during the study. Informed consent was obtained from the HD patients and further their doubts were clarified. Privacy was ensured throughout the study. Each day 15 study subjects were administered the set of framed questionnaires and $4 \mathrm{hrs}$ was spent to find the symptom experiences and bio-physiological parameters.

\section{Statistical data analysis}

The plan was analysed on the basis of objectives. Descriptive statistics namely frequency, percentage, mean and standard deviation were used to describe the data and inferential statistics such as chisquare were used to draw inferences of the data.

\section{Results}

Majority of the HD patients in this study were in the age group of 40-49 $(n=61,30.5 \%) \& 50-59(n=56,28 \%)$. Male dominated the study population with ratio $2.8: 1$. One third of them $(n=66,33 \%)$ were in the 7-12 months period of AV Fistula. Around $86 \%$ of them had Haemodialysis twice a week and $166(83 \%)$ of them were using diversional therapy (Table 2).

During AV Fistula cannulation, 74\% of study population had certain mental symptoms such as fear $(n=72)$, anxiety $(n=61)$, irritation $(n=124)$, anger $(n=44)$ and sadness $(n=103)$. The main physical symptom experiences by HD patients during AV Fistula cannulation was pain, drowsiness, fatigue, headache, palpitations, numbness, nausea/vomiting and, breathlessness. There was increase in pulse rate for $77 \%$ of population (154), increase in blood pressure, increase in the heart rate, and decrease in the respiratory rate was observed in more than $65 \%$ of population (Table 3 ).

There was significant association of mental and physical symptom experiences with bio-physiological parameters of HD patients during AV Fistula cannulation. The most relevant and highly significant were pulse rate due to fear and irritation and increase in hear rate and respiration due to pain and breathlessness (Table 4). 


\section{Discussion}

Renal function is vital for normal body function and its failure results in variety of diseases which results in a systemic failure of various body organs. Treatment of kidney failure heavily dependent on patient self-management of countless aspects of hospital and selfcare [6]. Hemodialysis is the choice of renal replacement therapy which require extensive hospitalization, economic burden and mental stress for the patients. Such situation badly affects the QOL of individuals coping with the stresses associated with life threatening chronic illness $[6,11,15]$. In the study we assay the symptom experienced by HD patients during the process. In the mental symptom experiences such as fear, irritation, anger, sadness and uncertainness were prevalent among HD patients and in regard with physical symptoms like pain, drowsiness, palpitations, fatigue, nausea/vomiting, breathlessness were present. Before the procedure HD patients had markedly varied changes in their pulse rate and an increased blood pressure and heart rate seen throughout the HD procedure. Not all but few mental and

Table 2. Frequency and percentage distribution of demographic variables of HD patients

\begin{tabular}{|c|c|c|}
\hline Demographic variables & Frequency (n) & Percentage (\%) \\
\hline \multicolumn{3}{|l|}{ Age } \\
\hline 20-29 years & 13 & 6.5 \\
\hline $30-39$ years & 34 & 17 \\
\hline 40-49 years & 56 & 28 \\
\hline $50-59$ years & 61 & 30.5 \\
\hline $60 \&$ above & 36 & 18 \\
\hline \multicolumn{3}{|l|}{ Sex } \\
\hline Men & 147 & 73.5 \\
\hline Woman & 53 & 26.5 \\
\hline \multicolumn{3}{|l|}{ Education } \\
\hline Illiterate & 31 & 15.5 \\
\hline Primary education & 84 & 42 \\
\hline Secondary education & 59 & 29.5 \\
\hline Graduate & 26 & 13 \\
\hline \multicolumn{3}{|l|}{ Occupation } \\
\hline Unemployed & 92 & 46 \\
\hline Permanent employee & 92 & 46 \\
\hline Daily wage & 16 & 8 \\
\hline \multicolumn{3}{|l|}{ Family income per month } \\
\hline Rs. $<3000$ & - & - \\
\hline Rs. $<3001-5000$ & - & - \\
\hline Rs. $<5001-7000$ & - & - \\
\hline Rs. $>7001$ & 200 & 100 \\
\hline \multicolumn{3}{|l|}{ Period of AV Fistula } \\
\hline $1-6$ months & 48 & 24 \\
\hline 7-12 months & 66 & 33 \\
\hline 13-18 months & 59 & 29.5 \\
\hline 19-24 months & 27 & 13.5 \\
\hline \multicolumn{3}{|c|}{ No. of Haemodialysis per week } \\
\hline Once & 28 & 14 \\
\hline Twice & 92 & 46 \\
\hline Thrice & 80 & 40 \\
\hline \multicolumn{3}{|c|}{ Sources of psychological support } \\
\hline Health professionals & 57 & 28.5 \\
\hline Family members & 101 & 50.5 \\
\hline Friends & 42 & 21 \\
\hline \multicolumn{3}{|l|}{ Use of diversional therapy } \\
\hline Yes & 166 & 83 \\
\hline No & 34 & 17 \\
\hline \multicolumn{3}{|l|}{ Duration of illness } \\
\hline In months & 34 & 17 \\
\hline In years & 166 & 83 \\
\hline
\end{tabular}

Table 3. Frequency and percentage distribution of mental symptom experiences of HD patients during cannulation

\begin{tabular}{|c|c|c|}
\hline & $\begin{array}{l}\text { Frequency } \\
\text { (n) }\end{array}$ & $\begin{array}{c}\text { Percentage } \\
\text { (\%) }\end{array}$ \\
\hline \multicolumn{3}{|l|}{ Mental symptoms } \\
\hline Fear & 72 & 36 \\
\hline Anxiety & 61 & 30 \\
\hline Irritation & 124 & 62 \\
\hline Anger & 44 & 22 \\
\hline Sadness & 103 & 51.5 \\
\hline Uncertainness & 52 & 26 \\
\hline \multicolumn{3}{|l|}{ Physical symptoms } \\
\hline Pain & 61 & 30 \\
\hline Drowsiness & 88 & 44 \\
\hline Fatigue & 114 & 57 \\
\hline Headache & 45 & 22.5 \\
\hline Palpitations & 154 & 77 \\
\hline Numbness & 59 & 29.5 \\
\hline Nausea/vomiting & 19 & 9.5 \\
\hline Breathlessness & 168 & 84 \\
\hline \multicolumn{3}{|c|}{ Bio-physiological parameters } \\
\hline$\uparrow$ Pulse rate & 154 & 77 \\
\hline$\uparrow$ Blood pressure & 130 & 65 \\
\hline$\uparrow$ Heart rate & 144 & 72 \\
\hline$\downarrow$ Respiratory rate & 168 & 84 \\
\hline$\downarrow \mathrm{spo}_{2}$ & 23 & 11.5 \\
\hline
\end{tabular}

Table 4. Association between the mental symptom experiences with bio-physiological parameters of HD patients during AV Fistula cannulation

\begin{tabular}{|c|c|c|}
\hline $\begin{array}{l}\text { Mental symptom experiences*/ } \\
\text { Bio-physiological Parameters }\end{array}$ & $x^{2}$ & p value \\
\hline Fear*pulse rate & 0.112 & $<0.01$ \\
\hline Fear*blood pressure & 0.124 & $<0.001$ \\
\hline Fear*heart rate & 0.112 & $<0.05$ \\
\hline Fear*respiration rate & 1.788 & $<0.05$ \\
\hline Fear*SpO & 0.369 & $<0.01$ \\
\hline Irritation*pulse rate & 8.954 & $<0.001$ \\
\hline Irritation*heart rate & 8.954 & $<0.01$ \\
\hline Anger*heart rate & 2.741 & $<0.01$ \\
\hline Sadness*blood pressure & 1.072 & $<0.05$ \\
\hline Uncertainness*heart rate & 2.665 & $<0.05$ \\
\hline \multicolumn{3}{|c|}{ Asterisks mark the significance level: ${ }^{*} \mathrm{p}<0.05,{ }^{*} \mathrm{p}<0.01, * * * \mathrm{p}<0.001$} \\
\hline $\begin{array}{l}\text { Physical symptom experinces* } \\
\text { bio-physiological parameters }\end{array}$ & $\mathbf{x}^{2}$ & p value \\
\hline Pain*pulse rate & 2.432 & 0.001 \\
\hline Pain*blood pressure & 2.065 & $<0.01$ \\
\hline Pain*heart rate & 2.432 & $<0.001$ \\
\hline Drowsiness*respiration rate & 5.092 & $<0.01$ \\
\hline Fatigue* pulse rate & 0.306 & $<0.05$ \\
\hline Fatigue*blood pressure & 3.19 & $<0.01$ \\
\hline Fatigue*respiration rate & 1.282 & $<0.001$ \\
\hline Palpitations*pulse rate & 7.569 & $<0.001$ \\
\hline Palpitations*heart rate & 7.569 & $<0.001$ \\
\hline Palpitations $* \mathrm{SpO}_{2}$ & 8.599 & $<0.01$ \\
\hline Nausea/vomiting*pulse rate & 5.073 & $<0.05$ \\
\hline Nausea/vomiting*heart rate & 5.073 & $<0.05$ \\
\hline Breathlessness*pulse rate & 4.237 & $<0.001$ \\
\hline Breathlessness*blood pressure & 0.688 & $<0.01$ \\
\hline Breathlessness*heart rate & 4.237 & $<0.001$ \\
\hline Breathlessness*respiration rate & 4.506 & $<0.001$ \\
\hline Breathlessness* $\mathrm{SpO}_{2}$ & 2.351 & $<0.05$ \\
\hline
\end{tabular}


physical symptoms were highly associated with the bio-physiological parameters such as fear and blood pressure, irritation and pulse rate, pain with pulse and heart rate, fatigue and respiratory rate, palpitations with heart rate, breathlessness with pulse rate, heart rate, and respiration rate. These findings are substantiated by a study was examined in the year 2003 about the association between quality of sleep and health related QOL in hemodialysis patients. In a study quality of sleep measured by Pittsburgh Sleep Quality Index (PSQI) and HRQOL using the Medical Outcome study showed that $71 \%$ of the subjects were poor sleepers due to higher prevalence of depression and lower HRQOL. This result indicates that ESRD influences on HRQOL [19].

To examine the psychometric properties of QLI, a study in the year of 1985 found that people with higher incomes had significantly higher QLI scores on the social and economic subscale though they are suffering with chronic diseases [20]. Depression is an important factor in cognitive impairment and the exercise of personal efficacy for adolescents undergoing haemodialysis [21]. A pilot study in the year 1980 reported a fair to poor quality of life for the majority of patients in unit hemodialysis [22]. Satisfaction and happiness during hemodialysis, peritoneal dialysis and transplant patients was found higher in younger patients indicating a better quality of life. Similar findings were reported earlier which state that education, race and marital status had a significant influence on quality of life [23]. A study assessed in the year 1993 showed that the quality of hemodialys is patients was found to be highest in the family and lowest in the health domain [24].

The depressive symptoms are very common at the start of dialysis therapy; and patients were more anxious and more depressed than transplanted patients. There is profound deficiency in QLI due to hypoalbuminemia, prevalence of anaemia, and depressive symptoms arising during and after dialysis therapy suggests the need for timely high quality predialysis care. Self-care efficacy and despair are the substantial predictors of quality of life; and there is substantial reduction in the quality of life in patients on maintenance with hemodialyis. Hemodialysis patients use to have significantly poorer quality of life in the area of physical, social cognitive and emotional functioning $[25,26]$. Renal transplant patients and hemodialyis patients have significantly good and high scores for the physical, general health and social functioning than those of hemodialyisis patients $[18,21,23]$.

\section{Conclusion}

Improvements in physical functioning result from exercise counselling and encouragement in hemodialysis patients. Hence more attention to patient level of physical activity is warranted to improve the quality of life. The findings of this study suggest that nursing and physicians' team should consider reducing problems of haemodialysis patients by training and counselling.

\section{Acknowledgment}

The authors would like to thank the Dean Research, Central research facility, Sri Ramachandra Institute of Higher Education and Research, Porur, Chennai-600116, India for assisting this study.

\section{References}

1. Sarnak MJ, Levey AS, Schoolwerth AC, Coresh J, Culleton B, et al. (2003) Kidney disease as a risk factor for development of cardiovascular disease: a statement from the American heart association councils on kidney in cardiovascular disease, high blood pressure research, clinical cardiology, and epidemiology and prevention. Circulation 42: 1050-1065. [Crossref]

2. Compu Mod software (1982) Kinetic information system. Redford, MI.

3. Glassock RJ, Winearls C (2009) Ageing and the glomerular filtration rate: truths and consequences. Trans Am Clin Climatol Assoc 120: 419. [Crossref]
4. Blacher J, Guerin AP, Pannier B, Marchais SJ, Safar ME, et al. (1999) Impact of aortic stiffness on survival in end-stage renal disease. Circulation 99: 2434-2439. [Crossref]

5. Gotch FA, Sargent JA (1985) A mechanistic analysis of the national cooperative dialysis study (NCDS). Kidney Int 28: 526-534. [Crossref]

6. Curtin RB, Mapes DL, Thomas-Hawkins C (2001) Health care management strategies of long-term dialysis survivors. Nephrol Nurs J 28: 385-392. [Crossref]

7. Inrig JK, Oddone EZ, Hasselblad V, Gillespie B, Patel UD, et al. (2007) Association of intra-dialytic blood pressure changes with hospitalization and mortality rates in prevalent ESRD patients. Kidney Int 71: 454-461. [Crossref]

8. Lindsay RM, Spanner E, Heidenheim AP, Lindsay S, LeFebvre JM (1991) The influence of dialysis membrane upon protein catabolic rate. ASAIO Trans 37: M134135. [Crossref]

9. Chen J, Gul A, Sarnak MJ (2006) Management of intradialytic hypertension: the ongoing challenge. Semin Dial 19: 141-145. [Crossref]

10. Shoji T, Tsubakihara Y, Fujii M, Imai E (2004) Hemodialysis-associated hypotension as an independent risk factor for two-year mortality in hemodialysis patients. Kidney Int 66: 1212-1220. [Crossref]

11. Sakkas GK, Gourgoulianis KI, KaratzaferiC, Liakopoulos V, Maridaki MD, et al (2008) Haemodialysis patients with sleep apnoea syndrome experience increased central adiposity and altered muscular composition and functionality. Nephro Dial Transplant 23: 336-344. [Crossref]

12. Marcora SM, Staiano W, Manning V (2009) Mental fatigue impairs physical performance in humans. J Appl Physiol 10: 857-864. [Crossref]

13. Inrig JK, Patel UD, Toto RD, Szczech LA (2009) Association of blood pressure increases during haemodialysis with 2-year mortality in incident hemodialysis patients: A secondary analysis of the dialysis morbidity and mortality wave 2 study. Am J Kidney Dis 54: 881-890. [Crossref]

14. Cantekin I, Tan M (2011) Determination of sleep quality and fatigue level of patients receiving continuous ambulatory peritoneal dialysis in Turkey. Scand J Urol Nephrol 45: 452-460. [Crossref]

15. Diener E, Sandvik E, Seidlitz L, Diener M (1993) The relationship between income and subjective well-being: Relative or absolute? Social Indicators Research 28: 195-223.

16. Musschenga AW (1997) The relation between concepts of quality-of-life, health and happiness. J Med Philos 22: 11-28. [Crossref]

17. Eiser C, Morse R (2001) A review of measures of quality of life for children with chronic illness. Arch Dis Child 84: 205-211. [Crossref]

18. McCann K, Boore JR (2000) Fatigue in persons with renal failure who require maintenance haemodialysis. J Adv Nurs 32: 1132-1142.

19. Iliescu EA, Coo H, McMurray MH, Meers CL, Quinn MM, et al. (2003) Quality of sleep and health-related quality of life in haemodialysis patients. Nephrol Dial Transplant 18: 126-132. [Crossref]

20. Ferrans CE, Powers MJ (1992) Psychometric assessment of the Quality of Life Index. Res Nurs Health 15: 29-38. [Crossref]

21. DiMatteo MR, Lepper HS, Croghan TW (2000) Depression is a risk factor for noncompliance with medical treatment: meta-analysis of the effects of anxiety and depression on patient adherence. Arch Intern Med 160: 2101-2107. [Crossref]

22. Deniston OL, Carpentier-Alting P, Kneisley J, Hawthorne VM, Port FK (2000)Assessment of quality of life in end-stage renal disease. Health Serv Res 24: 555. [Crossref]

23. Coburn JW, Salusky IB (1989) Control of serum phosphorus in uremia. $N$ Engl J Med 320: 1140-1142. [Crossref]

24. Lindsay RM, Henderson LW (1988) Adequacy of dialysis. Kidney Int Suppl 24: S9299. [Crossref]

25. Burton HJ, Kline SA, Lindsay RM, Heidenheim AP (1986) The relationship of depression to survival in chronic renal failure. Psychosom Med 48: 261-269. [Crossref]

26. Lin YJ, Lu KC, Chen C M, Chang CC (2012) The effects of music as therapy on the overall well-being of elderly patients on maintenance hemodialysis. Biol Res Nurs 14: 277-285. [Crossref]

Copyright: (C2019 Rachel K. This is an open-access article distributed under the terms of the Creative Commons Attribution License, which permits unrestricted use, distribution, and reproduction in any medium, provided the original author and source are credited. 